\title{
COVID-19 INFODEMIC AND PUBLIC TRUST FROM THE PERSPECTIVE OF PUBLIC AND GLOBAL MENTAL HEALTH
}

\author{
Miro Jakovljevic, Sarah Bjedov, Filip Mustac \& Ivan Jakovljevic \\ Department of Psychiatry and Psychological Medicine, University Hospital Centre Zagreb, Zagreb, Croatia
}

received: 25.9.2020;

revised: 20.11.2020;

accepted: 2.12 .2020

\begin{abstract}
SUMMARY
Crisis usually involves participants who trust and distrust each other, commonly in the same time. COVID-19 infodemic induced confidence crisis and distrust in authorities, science communities, governments and institutions can lead to harmful health behaviors and ill mental health and become a serious threat to public and global mental health as another kind of virus. Distrust mentality, conspiracy thinking and blame games may have detrimental effects not just on the individual level, but on the level of the whole groups, communities and global world. Public distrust and mistrust are related to the crisis in the domain of social and political relations, not only on the same country level, but also between different countries at regional or global level. Dynamics between public trust and mental health is a complex and bidirectional, ill mental health is causing and enhancing the inclination to confidence crisis, distrust, conspiracy theories and blame games and vice versa confidence crisis, distrust, conspiracy thinking and blame games are leading to ill mental health. It is important to have a holistic transdisciplinary integrative understanding of these dynamics and science-based treatment and prevention.
\end{abstract}

Key words: COVID-19 - infodemics - public and global mental health - social and public trust - compassionate society - empathic civilization

\section{INTRODUCTION}

Trust is fundamental to functioning in all fields of human endeavor in complex and interdependent communities, at national, international and global level, particularly in crisis times. It is essential component in positive and effective interpersonal relationships as well as in online communications, and without trust there is no partnership and good communication. Well-functioning communities promote trust as an important component of social capital, horizontally among people and vertically between people and their government. The COVID-19 pandemics is posing numerous and unprecedented challenges and threats worldwide such that we should reexamine our basic understanding of individual, public and global mental health from the multidisciplinary and trans-disciplinary scientific and philosophical approach as well as how human society and global world should operate in a new more better humanistic and secure way (Jakovljevic et al. 2020). Due to uncertainty, volatility, ambiguity, and high risks and hazards strongly associated with COVID-19 crisis we should be very cautious and open-minded as this pandemic goes forward (Kreps \& Kriner 2020). COVID-19 pandemic, syndemic and infodemic triad presents a unique test of social, political and professional trust associated with public and global mental health. Trust in experts and science, politicians and the public is going to be essential for the path out of the COVID-19 crisis. Understanding the dynamics of social, political and public trust, and their relations to individual, public and global mental health and how they facilitate and hinder behavior in crisis times is critical for successful managing COVID-19 infodemic negative effects.

Digital revolution in the $21^{\text {st }}$ century has been changing all fields of human life and it is very easy to be bewildered by information overload. COVID-19 infodemic as an over-abundance and rapid spread of information of all kinds, including rumors, gossip, unreliable information, misinformation, disinformation, fake news, theories of conspiracy and associated blame games and scapegoating has detrimentally influenced public, social and political trust as well as public and global mental health (Jakovljevic et al. 2020). Infodemic overabundance associated with multiple, dissonant and conflicting mental models makes it hard for many people to find trustworthy sources and reliable guidance in the Covid-19 crisis of confidence. Due to infodemics everyone has a private opinion and alternative truths, people commonly become confused, irrational, anxious, fearful, suspicious, xenophobic, even psychotic and prone to extreme behaviors. In USA, for example, partisan news reporting by Fox News contributed to rejection of the recommendations of Center of Disease Control, while $77 \%$ of Republicans believed that the media exaggerated the risks of COVID-19 (see Henderson et al. 2020). In many states of India, "contact-tracing and quarantining strategies have failed to a great extent precisely because people have not trusted the state and/or their neighbours to provide the required assistance during testing and isolation" (Jalan \& Sen 2020). According to the WHO 2020) the infodemic "continues to undermine the global response 
and jeopardizes measures to control the pandemic" polarizing public debate on topics related to COVID-19, amplifying hate speech, heightening the risk of conflict, violence and human right violations and threatening long-term prospects for advancing democracy, human rights and social cohesion". Misinformation is particularly dangerous in contexts with pre-existing low trust in institutions and low reliability of information given by scientists and experts. The link between dis/trust, mis/ information and non/cooperation has feedback effects propelling a vicious circle of inconfidence, suspiciousness, conspiracy theories, non-compliance and non-cooperation, blame-games and scapegoating which make health crisis impossible to be contained.

We agree with the claim of Heller (2020) that "pandemic is a physical exam of the social body, and never has public trust been put to a greater test" (see Jalan \& Sen 2020). According Jalan \& Sen (2020) in Kerala, a state in India, public trust was essential for "the acceptance of the state's pandemic actions and generated complementary private efforts, which in turn helped transform the state's actions into effective public actions". Trustworthy pandemic management depends not only on health care system and science, but also on political and social context that involves public trust, collective psychoculture (mind, mentality), public communication, democratic procedures, legal constraints, population uptake and compliance/alliance, digital contact tracing, etc. (see also Ranish et al. 2020). Authentic, accurate, reliable and science-based information and public trust is very important because without the appropriate trust, mutual respect, empathy, logic and correct information there is no successful management of COVID-19 crisis. The purpose of this paper is to promote ideas and practice of culture of trust, compassionate society and empathic civilization from the perspective of public and global mental health in order to support finding proper path out of the COVID-19 triad crisis and increase resilience to diseases and other adversities in the future.

\section{SOCIAL AND PUBLIC TRUST FROM THE PERSPECTIVE OF PUBLIC AND GLOBAL MENTAL HEALTH}

Trust issues are strongly associated with individual, family, public and global mental health because they are related to mental models and almost all personality dimensions: harm avoidance and novelty seeking behavior, persistence, self-directedness, cooperativeness and self-transcendence. Public/community mental health is a complex phenomenon bi-directionally related to the ability of people 1 . to survive, exist and thrive; 2 . to be relatively happy and in good well-being; 3 . to communicate with mutual reverence/respect, trust and empathy; 4. to work productively and creatively; 5 . to live meaningfully and successfully in their community.
Resilient and anti-fragile communities/societies, just like resilient and anti-fragile families, are predicated on mutual trust, respect, empathy, altruism, and feedback learning abilities of their members. Trust associated with reverence is social glue, essential force that holds humans, community, society and civilization together which is very important for survival, resilience and antifragility. It is a fundamental component of health care in general, as well as in the fighting COVID-19 pandemic, syndemic and infodemic triad. As a complex, multidimensional and dynamic interrelationship of numerous factors, public trust and its components may vary significantly over time and between different communities. Public trust can partly explain why some countries have adopted and enforcing harsh policies, while others are relying primarily on recommendations (Harring et al. 2020). COVID-19 infodemic confirms how trust is hard to build but rather easy to ruin, particularly when different social groups in community or countries have different demands, interests and alternative trues. Uncritical harsher policies commonly have negative effects on public trust and induce vicious circles. All citizens in some community as well as people all over the world should make sacrifices for the collective good, but according the social dilemma, many people are not ready to accept personal cost for benefits that are mainly collective (Harring et al. 2020), particularly in societies with psychoculture of narcissism which sustain individualism, self-interest and self-sufficiency (Gerhards 2011). We live in a narcissistic-manic mental culture of spectacle, hedonism, marketism and consumerism, pervaded by paranoid and nihilistic cultures of distrust, conflicts, terrorism and wars (Jakovljevic \& Tomic 2016) characterized by fragile basic trust. Psycho-culture or culture of mind is individual and collective frame of reference with our deeply ingrained beliefs and attitudes about life and world, with systems of values and life orientations which modulate our thinking, emotions and behavior as well as the manners how we create our relationships, narratives and life stories (Jakovljevic \& Tomic 2016). Empathic humanistic psycho-culture involves positive thinking and beliefs (basic trust, "we are OK, you are OK, and they are OK"), positive affectedness (love, empathy, compassion, kindness, generosity, forgiveness), altruistic motivation (it is good to work for good because we are better and worthier if we respect, support and help others") and cooperative behavior ("win-win behavioral strategies" instead of zero-sum games).

Trust may be conceptualized, defined and operationalized in many ways what is done in different disciplines. Here are some examples: "belief in the honesty and integrity of another" (Corsini 2002); "assured reliance on the character, ability, strength, or truth of someone or something" (The Meriam-Webster Dictionary 2020); "to believe that someone is good and honest and will not harm you, or that something is safe and 
reliable, and "to hope and expect that something is true" (The Cambridge Dictionary 2020). In short one can say it is a firm belief in the reliability, truth, ability, strength and good intentions and influence of someone or something. The majority of definitions stress the positive and optimistic acceptance of a vulnerable situation in which the truster believes the trustee will respect and care for the truster's interests (Laugharne \& Priebe 2006). It is important to stress that trust issues, characterized by beliefs or fears of harm, manipulation and betrayal, may have self-protecting as well as self-sabotaging effects. Trust is relational phenomenon that involves a feedback loop where experience or information distribution and media can reinforce trust or lead to a sense of betrayal or mistrust and distrust. Trust is related to credibility and it involves five dimensions and drivers: 1. competence: ability to meet challenges and goals and to achieve the wishful results and outcomes; 2. fidelity: reliability and consistency in pursuing interests of relevant parties; 3. confidentiality: protecting private information; 4. honesty and openness: disclosure, veracity, telling the truth and avoiding falsehoods, misinformation and fake news; 5 . faith: to rely on, to believe in (see also Laugharne \& Priebe 2006). Trust is both a logical process involving reason (assessing the probabilities of gain or loss) and emotional process (one feels that may have trust, emotional satisfaction) process and humans trust others and institutions because they have experienced their trustworthiness, they have got information about them and because they have faith in good human nature (Aljazzaf \& Capretz 2010). It is the capability to predict the behavior of another party or veracity, truthfulness and credibility of information. Building blocks of trust are: authentic communication, competence, support, boundaries, contact, positive intent and forgiveness (Bibb \& Kourdi 2004).

Public mental health is predicated on public trust and positive and creative behavior between people supporting collective well-being and common security. Public trust is positively related to the compliance or alliance of people to accept personal and collective protective measures in crisis times such as COVID-19 triad crisis. Some research indicated that trust was associated with lower COVID-19 mortality rates and later adoption of restrictive lockdown measures (see Devine et al. 2020). Professional trust, degree to which the public believes that the profession promotes and protects the common public's interest, has a significant role for responding to the pandemic health crisis. Psychoculture ("cultura animi" according Cicero) is related to the cultivation of soul or mind producing individual and collective mental models, deeply ingrained assumptions, beliefs, attitudes, pictures and visions that influence how we understand the world and how we operate in the world and create our narratives and life stories (Jakovljevic \& Tomic 2016). Mental models are about mental functioning, information processing and experiencing and defining the self and others where "the others" may be defined or perceived with various degrees of likeness, trust and respect/reverence, either as friends, rivals, or enemies (Jakovljevic et al. 2019). General social trust, which involves three important components trust in people we know, trust in people we do not know, and trust in Government, increases group solidarity, cooperation and cohesion (Alessandri et al. 2020). Song \& Yoo (2020) classify social trust into trust in public organizations, e.g. government, trust in the general public, and trust in personal communication. Disposition to trust or distrust has two components: Faith in Humanity and Trusting Stance (McKnight \& Chervany 2020). Faith in Humanity refers to underlying assumptions and beliefs that people are usually honest, benevolent, competent and predictable, while Trusting Stance is about personal strategy or choice to trust others based on subjective calculation of risk-benefit ratio. Trusting Belief-Competence refers to situations where truster believes that trustee has the capacity or power to work for good of truster or what truster needs to be done. Trusting Belief-Benevolence refers to situations where truster believes that trustee cares about truster and is motivated to work for good of truster. Trusting Belief-Integrity refers to situations when truster believes that trustee makes good faith agreements, tells the truth, and fulfills promises. Trustingbelief-predictability refers to situations that truster believes that trustee's behavior, good or bad, is consistent enough that truster forecast it. There is negative relationship between dark triads of personality traits: 1. narcissism (a lack of modesty, high interpersonal dominance, selfishness, need for attention), 2. machiavellianism (a lack of empathy, manipulation and the use of exploitative tactics, amorality, cynical worldview), and 3. psychopathy (callousness and un-sentimentality, apathy, impulsiveness and lack of self-control, irresponsibility, low affect, absence of remorse and guilt) and general social trust (see Alessandri et al. 2020). Social trust, an important component of social capital, is predicated on cultural values to have trust or distrust in other people as well as on personal experience and it is important for mental stability in communication with others (Song \& Yoo 2020). According psychoanalyst Erik Erikson (1902-1980) the trust versus mistrust is the first of 8 stages of psychosocial development which happens in the first year of life when a child in the case of successful resolution comes to feel that the world is trustworthy. The unsuccessful resolution of this phase results in low self-esteem and basic mistrust in others and environment. The development of the basic trust or hope is fundamental for the development of self-esteem and positive and healthy relations as well as for interpersonal trust in the honesty and integrity of other people. Some authors differ three type of trust: 1 . trust as a 'leap of faith' or willingness to be vulnerable, 2. trust as a component of social capital; 3. trust as a component of power-knowledge or truth-telling (see Leith 2013). 


\section{COVID-19: A UNIQUE DISASTER BUT ALSO AN OPPORTUNITY TO INCREASE PUBLIC TRUST, RESILIENCE AND ANTI-FRAGILITY}

Due to the COVID-19 global crisis common security, resilience and antifragility has become fundamental issues as well as the connection between social and political trust on one side and governmental and citizen responses to the pandemic on the other side. Concept of common security which imposes mutual responsibility and trust is predicated on creation of collaboration, resilience and antifragility that can extend across global, international, national, familial, and personal levels of experience (see Rogers 1991). Resilience and antifragility are similar concepts with some differences. In crisis and adversities some systems, persons or communities are fragile and breakdown under pressure, while others remain resistant, adaptive and resilient, and some even thrive and grow. Resilience is usually defined as individual and group/ community ability to withstand, recover and even grow and be stronger after stress, adversity, crisis, disease and disaster and it involves biological, psychological, social and spiritual dimension of human existence (Jakovljevic 2017, 2018, Jakovljevic \& Borovecki 2018). The anti-fragility is defined as ability or convex response of some systems, individuals and communities to take the opportunity of disaster to evolve, grow and thrive, becoming more resilient later (Taleb 2013, Wikipedia 2020). Good news is that individual, family and community resilience and antifragility can be enhanced through learning and training. COVID-19 crisis can reorder our world in dramatic ways, for better or worse. It may force us to reconsider ourselves and our world, who we are and what values we follow, it could incite us to rediscover better version of ourselves and the world. It may induce the rising of human goodness: empathy, compassion, altruism, generosity of spirit and action in order to improve the world that is commonly a hostile place, full of insecurity, conflicts and dangers. Hodegetics (Greek hodos - way, guidance, indicator of way, pointing the way) of moral courage and universal ethics for brotherhood in humanity is very important for promotion of resilience and antifragility because it enhances the capacity to move ahead in spite of despair. Moral courage is the cornerstone for the virtues such as love, compassion, caring, trust and fidelity (see Oliner 1991. A critical number of harmonious leaders with integrity in all fields of our life such as politics, science, religion, education, business, culture, etc. are needed to gain momentum for adopting these virtues in global social and political reality.

All parts of society have a role to play in promoting public mental health, resilience and antifragility. Psychiatrists and psychologists are important to facilitate these processes. Promotion of public mental health involves enhancing community well-being and resilience against COVID-19, promoting better disease recovery and antifragility, and reducing or preventing consequences. A public mental health strategy can enhance resilience and antifragility and help individuals cope with the adversities in life as well as maximize their engagement with their community to improve well-being, self-esteem and life choices, and achieve success in their roles as parent, carer and worker (Royal College of Psychiatrists 2010). Social and spiritual capitals in a community are very important elements of community resilience and anti-fragility during COVID-19 crisis periods. Mutual respect, responsibility, empathy and public, social and political trust are going to be essential for the path out of the COVID-19 syndemic crisis. Public relations, trust and creative communication are crucial for pandemic management. Efficient protection from COVID-19 comes from the global solidarity and sharing of reliable scientific information and knowledge that prevent theories of conspiracy and psychological battles. The spread of epidemic in any country endangers the whole humankind inducing pandemic. COVID-19 crisis can be effectively overcome only in the spirit of mutual respect, trust and global co-operation (see also Harari 2020). All countries need to share information globally and humbly seek advice and help. Global co-operation is crucial in production, clinical trials and distribution of medical equipment like anti-COVID-19 drugs and vaccines, testing kits, respiratory machines, etc. Rich countries should be willing to help poorer countries sending them medical equipment and drugs. Countries currently less affected should send medical stuff to the worst-hit countries. Given the long-lasting global nature of the economy and supply chains, there is an urgent need for a global plan of action. As every crisis is also an opportunity for better future let's hope that COVID-19 pandemic will help humankind realize the importance of public and global health and building of compassionate society and empathic civilization. $\mathrm{Hu}-$ mankind is at the cross-roads: to travel down the route of global disunity, selfish society, and narcissistic and paranoid psycho-cultures or to choose the path of global solidarity, humanistic psycho-culture, and empathic civilization (see Jakovljevic et al. 2019 ).

In the crisis like this one with COVID-19 people are prone to discover hidden resilience potentials of altruism, empathy, trust and amity and help one another. In COVID-19 context one can think on four levels: on the individual level, on local community level, on national level, and at the global level. Different communities and cultures have different inherent characteristics and mechanisms involving different levels of trust in relationships which determine how well they can resist the negative effects. Resilient societies, like resilient families, depend on their members' ability to create and maintain good relationships 
based on human dignity, respect, trust, cooperation, compassion and empathy. Moral psychology shows that empathy and trust act as social glue, increases cohesiveness and cooperation between individuals as well as between communities and societies. Resilient and anti-fragile communities tend to foster a culture with shared values, a shared mission or goal, open and authentic leadership, use of consensus not force, enjoyment of work, a positive atmosphere, a safe learning environment, and honest and authentic conversations (see Sinay et al. 2016). Culture involves a set of beliefs, norms, material and non-material values and behavioral patterns shaping the members' behavior and building the core identity of communities. Trust is valuable psychological, social and spiritual currency and fundamental to creativity, innovation, individual and collective identity, purpose and meaning of life. Low-trust communities are commonly plagued by leader scepticism, cynicism, irrational behavior, fear and cunning communication styles (Sinay et al. 2016). Culture of trust (see table 1 and 2) is an antithesis and alternative to culture of fear and force in our liquid reality (Sinay et al. 2016).

Trust is embedded in community rules, roles, and relations, in everything that members do or try to do in interpersonal communication and institutional activities forming mutually beneficial relationships. The three Stages of Trust Development are metaphorically described as tactical climbing (initiating trust - coordinated actions of participants to increase levels of reciprocal risk), gardening (the ongoing growth of trust from increasing knowledge of other participants sustaining trust, breaking and repairing trust) and musical harmonizing when participants collectively identify with the community through learning and social interactions (Sinay et al. 2016). Trust may be personal and collective phenomenon (see Bibb \& Kourdi 2004, Harris et al. 2013): self-trust (the trust we needed to be confident in our capabilities and judgments in given situations), relational-trust (the trust we put in another person or group, a generalized type of trust established over time), structural trust (the trust we put in country, institutions, companies and brands), transactional trust (the specific trust, commonly one-off and pertains to a particular context). Culture of trust (see table 1 and 2) can only flourish in communities where values such as common well-being, honesty, confidence, responsibility, professionalism, and good governance or transformational leadership are practiced. Trusting communication beyond national, religious and racial differences promotes people's connectedness, engagement, and readiness leading to partnership, harmony, creativity, peace and better outcome in general. According Fukuyama (1995) prosperous countries are usually those where business relations between people can be practiced flexibly on the basis of trust. In every community, local, national or global, culture of trust is essential component of the social and spiritual capital upon which soft power operates and which comes from values and moral authority.

Table 1. Characteristics of a Culture of Trust (Sinay et al. 2016)

Shared values: Values which are practiced a work but meaningful to employees outside of work

A shared mission or goal: Employees' commitment to communal goals, and not simply personal/independent goals Open and authentic leadership: A propensity of a leader to demonstrate trust, among other values, towards employee

A culture of consensus not force: Employees willingly contribute to shared missions or goals if there is a culture of trust, otherwise, employees may feel pressured or coerced to do so

A feeling of enjoying work: A culture of trust is fostered if employees feel relaxed and sense that mistakes and failure are accepted

An atmosphere of fun and enjoyment: $A$ workplace where employees can have fun, by themselves, and are open to pushing intellectual (i.e. ideas, concepts) boundaries

A desire to learn, not blame: Fault associated with mistakes and failure does not nurture openness, trust, and ongoing development among employees

Honest and authentic conversations: A culture of trust is fostered where there is sincere communications and information is not withheld across horizontal and vertical relationships

Source: Bibb \& Kourdi 2004

Table 2. Facets of trust in school settings (Sinay et al. 2016)

Benevolence: Having confidence that another party will at in one's best interests

Competence: Depending on a person's knowledge, skills, and competence to do their job

Honesty and Integrity: The consistency between words and actions. Doing what is right and demonstrating a commitment to shared beliefs or values

Openness and Transparency: Sharing of information and transparency of one's actions or plans

Personal Regard: Caring for others

Reliability or Consistency: The predictability of behavior and the confidence that one's needs shall be met

Respect: Recognizing other people's value and demonstrating this value by listening and considering their views 


\section{PSYCHIATRY FOR A BETTER WORLD: EMPATHY PARENTING AND EDUCATION FOR CULTURE OF TRUST, COMPASSIONATE SOCIETY AND EMPATHIC CIVILIZATION}

We live in the infodemic world divided into good guys and bad guys and people have a pro-us illusion of knowledge related to the relative truths, alternative truths and fake news, massive media manipulation and "we-they" schisms. There is a growing feeling associated with many evidence that things have got to change, but the question is how. Psychiatry and mental health sciences have been challenged how to define and treat an increasing number of public and global mental health problems and dangerous individual, group and collective (political too) behaviors. Considering the advanced needs of the current era, Community Mental Health Sciences and Disciplines are to induce education for transformation into culture of trust, compassionate society and empathic civilization. Fundamental questions here arise: 1. why culture of trust, compassionate society and empathic civilization is needed; 2 . what are strengths and weakness, opportunities and threatens; 3. what kind of world do we want, what kind of global leadership, global government and global institutions; 4 . how can we achieve it; and 5. is it science fiction and utopian dream. Trust, empathy and compassion complementary to each other are key factors in building effective understanding, communication, and healthy and creative relationships in all human communities. They are also essential in finding solutions to problems, resolving conflicts and crisis such as the current COVID-19-related one. Empathy has cognitive, emotional and behavioral dimensions so that we can speak about compassionate empathy, cognitive empathy, and emotional empathy (Rahman 2016). Cognitive empathy is ability to recognize how and what other people are feeling. Emotional empathy is capability to feel what and how other people are feeling. Compassionate empathy is desire and readiness to other people deal with their problems and emotions. Trust is usually established when people understand, wish and try to help each other. People all over the world are beginning to recognize their common humanity and to agree that selfish societies and narcissistic psychoculture are not an option for better future. As the COVID-19 pandemic is a big global problem, we urgently need a global consensus about the rules and procedures by which the global community operates in the best interest of the humanity as a whole (Jakovljevic et al. 2020b). Successful community "transforms the dross of our differences into golden harmony" (see Peck 1987) of national unity and global solidarity. The logic of human destiny shows that at every stage of human development there has been "a general tendency for humans to form larger and larger groups that lead to a net improvement in human welfare" (Malone 2019). Experience of harmonious relations in community shows us that when people are involved in solving common problems, then intergroup distrust, deceit, polarization and aggressive confrontation decrease significantly while mutual understanding, trust, reverence and cooperation increase. Concepts of culture of trust, compassionate society and empathic civilization are predicated on non-zero-sum thinking and win-win interactions, collective intelligence, collective self, and global mind. According to Malone (2019) global mind is "a perspective, a way of looking at the world" similar to the concepts of noosphere (Greek noo mind, intellect), the sphere of human consciousness and mental activity Teilhard de Chardin 1964) and global brain (Russel 1983, Bloom 2000). A wise global mind as the end of point of the process of global-scale integration of all the people, computers, and other forms of intelligence involves "the greatest good for the greatest number" and "serving a purpose larger than yourself" (Malone 2019).

The generic organizational skills that give mankind a chance to boost resilience and antifragility in the current COVID-19 pandemic crisis and to promote culture of trust, compassionate society and empathic civilization involve 1 . humanistic transformational leadership; 2. creative thinking and clear vision and values; 3 . authentic communication and reliable informing and trust; 4. culture of empathy, common security and well-being, dialogue and cooperation; and 5. collective feedback learning (see also Al-Azri 2020). We need a clear vision of the humanistic psycho-culture, global mind and humanistic self, compassionate society and empathic civilization instead of global disunity, selfish societies, blame games and narcissistic, paranoid and nihilistic psychocultures (see Jakovljevic et al. 2020). Humanistic leadership is very important to overcome infodemic crisis. COVID-19 crisis is an opportunity for better future if humankind recognizes humanistic leadership as a mindset that diffuses through communities, national, international and global institutions. Trust is one of the fundamental forms of capital a humanistic leader has and it has three core drivers: authenticity, logic and empathy. Authentic communication and reliable informing with critical information is a key element for establishing and maintaining public trust and successful infodemic management. Art and practice of learning organization (systems thinking, collective learning, vision, mental model and mastery) is fundamental for changing and adapting behavior related to resilience and antifragility in crisis situations as response to information that flow within system or come from outside system. The wise navigating the collective hero's journey through the COVID-19 infodemic (Jakovljevic 2020) is associated with smarter sensing and learning as well as with working together in new ways. The concepts of the global mind with the greatest good for the greatest 
number and serving the purpose larger than individual profit may sound too many people as science fiction as well as the concepts of culture of trust, compassionate society and empathic civilization as utopia, vague mysticism with stories for naïve optimists. However, if more and more intelligent people with this vision of betterharm future become more and more proactively connected, this vision will become more and more reality. Trust, empathy and compassion give us the power to improve parenting, transform schools and change our communities and the world. In some countries like Denmark which is among the top three happiest countries in the world, empathy education is a fundamental part of the school curriculum. Finland is a "high trust country" where public institutions enjoy high public trust and where honesty and trust are among the most basic values and building blocks of Finish society (see Harris et al. 2013). Toronto District School Board promotes fostering a "Culture of Trust" within and outside a school system and offers very useful recommendations (Sinay et al. 2016). Empathic parenting establishes basic trust and trustful school systems foster appropriate mental models and interpersonal relations as a background for culture of trust. Empathy and trust help build creative and positive relationships, increases efficacy in work, prevent bullying and misbehavior, promotes the growth of humanistic leaders, prophets, influencers and managers. Psycho-education for empathy, compassion and trust involves 10 competencies: authenticity, emotional literacy, moral identity, perspective taking, moral imagination, self-regulation, practicing kindness, collaboration, moral courage and altruistic leadership, service and stewardship (see Borba 2018). Psychoeducation ought to be directed to all classes, cultures, nations and countries promoting and converging individual, family and collective transformation and institutional transformation at national and international levels.

Culture of trust, empathy and compassion is made through virtues and values which people practice and live on daily basis. New morality or a new moral framework of a universal ethics is needed in private life as well as in public, cultural, business and political life. Politicians have to become more moral than they currently are (Oliner 1991). Spirituality as combination of self-transcendence, trust/faith, love, empathy, altruism and meaning in life is very important dimension in psychoeducation for new morality of compassionate society and empathic civilization. Primary function of the all major world religions is to explain the origin and meaning of life and foster education for unselfish love that all human beings could be spiritually brothers and sisters (Oliner 1991). Religious networks which circle all over the world have common goals, concerns and activities in the areas of reverence for life, compassion, solidarity and cooperation. The mental health sciences and disciplines should be more engaged in research, exploration and promotion of psychoeducation for culture of trust, compassionate society and emphatic civilization. Concepts of culture of trust, compassionate society and empathic civilization may seem as a utopian dream or in better case a far-reaching reality. Good news is that trust, compassion and empathy can be learned through psychoeducation in families and schools and practice in everyday life and all institutions. Wisely navigating the hero's journey through the COVID-19 infodemic darkness gives us the challenging opportunity to enter the dawn light of culture of trust, compassionate society and empathic civilization. Human species may thrive only on mutual trust, love, empathy and compassion related to new morality, spirituality, interconnectedness and cooperation. Psychoeducation as an art and practice of learning organization and hodegetics for compassion and empathy, resilience and antifragility may help more successful overcoming COVID-19 crisis.

\section{CONCLUSIONS}

Public trust, both horizontally among people and vertically between people and their institutions is very important for overcoming COVID-19 pandemic, syndemic and infodemic triad. The lessons learned from the COVID-19 tragedies should lead to new strategies for substantial changes in many aspects of our life. Brotherhood in humanity is a life philosophy that all human beings belong to a single family/community based on shared logos, thelos, pathos, ethos and mythos. This philosophy is fundamental for public and global mental health which is predicated on universal human rights, trust, love, reverence, empathy and compassion. The authenticity, accuracy, timelines, relevance and significance and applicability of the information being communicated associated with humanistic mental models are fundamental for public and global trust in overcoming COVID-19 crisis. Proper understanding of trust provides the background to establish trustful relations in fighting COVID-19 and promoting brotherhood in humanity, compassionate society and empathic civilization.

\section{Acknowledgements: None.}

\section{Conflict of interest: None to declare.}

\section{Contribution of individual authors:}

Miro Jakovljevic: concept and design of article, literature searches, writing manuscript, approval of final version.

Ivan Jakovljevic, Sarah Bjedov \& Filip Mustac: comments on the concept of article, literature searches, writing some parts of manuscript, approval of the final version. 


\section{References}

1. Al-Azri NH: Antifragility amid the COVID-19 crisis: Making healthcare systems thrive through generic organisational skills. Editorial. Sultan Quaboos University Med J, 2020:20:e241-244.

https://doi.org/10.18295/SQUMI.2020.20.03.001

2. Aljazzaf $Z$ \& Capretz MAM: Online trust: Definitions and principles. Conference paper. 2010.

https://www.researchgate.net/publication/224193095

3. Alessandri G, Filosa L, Tisak MS, Crocetti E, Crea G \& Avanzi L: Moral disengagement and generalized social trust as mediators and moderators of rule-respecting behaviors during the COVID-19 outbreak. Frontiers in Psychology 2020; 11. Article 2102.

doi:10.3389/fpsyg.2020.02102

4. Bibb $S$ \& Kourdi J: Trust matters for organizational and personal success. Palgrave Macmillan, Basinstoke \& New York, 2004

5. Bloom H: Global Brain: The Evolution of Mass Mind from the Big Bang to the $21^{\text {st }}$ Century. Wiley, New York, 2000

6. Blum K, Cadet JL, Baron D, Badgayian RD, Brewer R, Modestino EJ \& Gold M: Putative COVID-19 induction of Reward Deficiency Syndrome (RDS) and associated behavioral addictions with potential concomitan dopamine depletion: Is COVID.19 social distancing a double edged sword? Substance Use \& Misuse 2020. https://doi.org/10.1080/10826084.2020.1817086

7. Borba M: Empathy education - Why the other side of the report card counts.Twitter@micheleborba2018 www.hilliardschools.org

8. Cambridge Dictionary: Trust. dictionary.cambridge.org 2020

9. Corsini R: The Dictionary of Psychology. BrunnerRoutledge, New York 2002

10. Devine D, Gaskell J, Jennings $W$ \& Stoker G: Trust and the coronavirus pandemic: What are the consequences of and for trust? An early review of the literature. Political Studies Review 1-12, 2020 doi:10.1177/1478929920948 684journals.sagepub.com/home/psrev

11. Fukuyama F: Trust: The Social Virtues and the Creation of Prosperity. The Free Press, New York, 1995

12. Gerhardt S: The Selfish Society - How We All Forgot to Love One Another and Made Money Instead. Simon \& Shuster, London, 2011

13. Harari YN: The world after coronavirus. Financial Times, March 20, 2020

14. Harring N, Jagers SC \& Loefgren A: COVID-19: Largescale collective action, government intervention, and the importance of trust. World Development 2021 (138) 105236 https://org/10.1016/j.worlddev.2020.105236

15. Harris J, Caldwell B \& Longmuir F: Literature review: $A$ culture of trust enhances performance. Australian Institute for Teaching and school leadership, June 2013.

16. Henderson J, Ward PR, TonkinE, Meyer SB, Pillen H, McCullum D, Toson B, Webb T, Coveney $J \&$ Wilson A: Developing and maintaining public trust during and postCovid-19: Can we apply a model developed for responding to food scares. Front. Public Health 2020; 8:369 doi: 10.3389/fpubh.2020.00369

17. Jakovljevic $M$ \& Tomić Z: Global and public mental health promotion for empathic civilization: The role of political psychocultures. Psychiatr Danub 2016; 28:323333
18. Jakovljevic M: Resilience, psychiatry and religion from public and global mental health - From divide to dialoque and cooperation in the search for humanistic self, compassionate society and empathic civilization. Psychiatr Danub 2017; 29:238-244. https://doi.org/10.24869/ psyd. 2017.238

19. Jakovljevic $M \&$ Borovecki F: Epigenetic, resilience, comorbidity and treatment outcome. Psychiatr Danub 2018; 30:242-253. https://doi.org/10.24869/psyd.2018.242

20. Jakovljevic M: Empathy, sense of coherence and resilience bridging personal, public and global mental health and conceptual synthesis. Psychiatr Danub 2018; 30:380384. https://doi.org/10.24869/psyd.2018.242

21. Jakovljevic $M \&$ Jakovljevic I: Theoretical Psychiatry as a Link between Academic and Clinical Psychiatry. U KimYK (ur): Frontiers in Psychiatry - Arteficial Intelligence, Precision Medicine, and Other Paradigm Shifts, 355-398. Springer Nature Singapore Pte Ltd, 2019

22. Jakovljevic M, Kurjak A, Jerkovic A, Hasanovic A \& Nikic M: Spirituality, religiosity and nationalism from the perspective of public and global mental health. Psychiatr Danub 2019; 31:382-391. https://doi.org/10.24869/psyd.2019.382

23. Jakovljevic M: COVID-19 crisis as a collective hero's journey to better public and global mental health. Psychiatr Danub 2020; 32:3-5. https://doi.org//10.24869/psyd.2020.3

24. Jakovljevic M, Jakovljevic I, Bjedov $S$ \& Jaksic $N$ : COVID-19 pandemia and public and global mental health from the perspective of global health security. Psychiatr Danub 2020; 32:6-14. https://doi.org/10.24869/psyd.2020.6

25. Jalan $J \&$ Sen A: Containing a pandemic with public actions and public trust: the Kerala story. Indian Economy Review, published online: 28 July 2020. https://doi.org/10.1007/s41775-020-00087-1

26. Kreps SE \& Kriner DL: Model uncertainty, political contestation, and public trust in science: Evidence from the COVID-19 pandemic. Science Advances 2020; 6:eabd456321 October 2020

27. Laugharne $R \&$ Priebe S: Trust, choice and power in mental health: A literature review. Social Psychiatry and Psychiatric Epidemiology 2006; 41:843-852. doi:10.1007/s00127-006-0123-6

28. Leith D: Representations of the concept of trust in the literature of Library and Information Studies. Cosmopolitan Civil Societes Journal 2013; 5:54-74.

http://utsescholarship.lib.uts.edu.au/epresss/journals/inde x.php/mcs

29. Malone TW: The global mind. In Malone TW: Superminds - How Hyperconnectiviry is Changing the Way We Solve Problems, 317-327. Oneworld Publications, London, 219

30. McKnight DH \& Chervany NL: Trust and distrust definitions: One bite at a time. Michigan State University 2020 msu.edu

31. Merriam-Webster Dictionary: Definition of Trust. www.meriam-webster.com accesed 13 Dec. 2020

32. Oliner SP: Altruism: Antidote to War and Human Antagonism. In Offerman-Zuckerberg J: Politics and Psychology: Contemporary Psychodynamic Perspectives, 277 301. Plenum Press, New York, 1991

33. Rahman WAWA: Empathy and trust: Into a better workplace environment. Journal of Bussiness and Economics 2016; 1:2025-2034. doi:10.15341/jbe(21557950)/12.07-2016/009 www.academicstar.us 
34. Ranish R, Nijsingh N, Ballantyne A, van Bergen A, Buyx $A$, Friedrich $O$, Hendl T, Marckmann $G$, Munthe $C \&$ Wild $V$ : Digital contact tracing and exposure notification: ethical guidance for trustworthy pandemic management. Ethics and Information Technology, published online. 21 October 2020 https://doi.org/10.1007/s10676-020-09566-8

35. Rogers RR: Common security - The only way. In Offerman-Zuckerberg J: Politics and Psychology: Contemporary Psychodynamic Perspectives, 231-237. Plenum Press, New York, 1991

36. Romagnolo A, Balestrino R, Imbalzano G, Ciccone $G$, Riccardini F, Artusi CR, Bozzali M, Ferrero B, Montalenti E, Montaanaro E, Rizzone $M G$, Vaula $G$, Zibetti $M$ \& Lopiano L: Neurological comorbidity and severity of COVID-19. Journal of Neurology 2020; August 4, published online https://doi.org/10.1007/s00415-020-10123-y

37. Royal College of Psychiatrists: No Health Without Public Mental Health- The Case for Action. Position Statement PS4/2010, London October 2010

38. Russel P: The Global Brain: Speculations on the Evolutionary Leap to Planetary Consciousness. J.P. Tarcher, Los Angelos 1983
39. Sinay E, Presley A, Douglin $M$ \& De Jesus: Board: Fostering a "Culture of Trust" within and outside a school system. Research Report 2016; No 15/16-11. Toronto, Ontario, Canada: Toronto District School Board

40. Song E \& Yoo HY: Impact of social support and social trust on public viral risk response: A COVID-19 survey study. International Journal of Environmental Research and Public Health 2020; 17:6589. doi:10.3390/ijerph17186589

41. Taleb NN: Antifragile: Things That Gain From Disorder. Penguin Books, London, 2013

42. Teilhard de Chardin P: The Future of Man. Collins, London, 1964

43. Troyer EA, Kohn JN \&Hong S: Are we facing a crashing wave of neuropsychiatric sequelae of COVID-19? Nuropsychiatric symptoms and potential immunologic mechanisms. Brain, Behavior and Immunity 2020; 87:34-39. https://doi.org/10.1016/j.bbi.2020.04.027

44. WHO: Managing the COVID-19 infodemic: promoting healthy behaviours and mitigating the harm from misinformation and disinformation. Join statementby WHO, UN, UNICEF, UNDP, UNESCO, UNAIDS, ITU, UN Global Pukse, and IFRC. 23 September 2020. www.who.int

45. Wikipedia: Antifragility. En.m.wikipedia.org

Correspondence:

Professor Miro Jakovljevic, MD, PhD

Department of Psychiatry and Psychological Medicine, University Hospital Centre Zagreb

Kispaticeva 12, 10000 Zagreb, Croatia

E-mail: jakovljevic.miro@yahoo.com 